\title{
Hiding Data in Halftone Images
}

\author{
Hsien-Wen TSENG \\ Library of National Taichung Teachers College \\ Taichung, Taiwan 403, R.O.C. \\ e-mail:wen@mail.ntctc.edu.tw
}

\section{Chin-Chen CHANG}

Department of Computer Science and Information Engineering

National Chung Cheng University

Chaiyi, Taiwan 621, R.O.C.

e-mail: ccc@cs.ccu.edu.tw

Received: April 2005

\begin{abstract}
Most recent papers about visual cryptography for halftone images are dedicated to get a higher contrast decoded image. However, the hidden visual pattern often blends into the background image and leads to a confused image. In this paper, we propose an improved method for halftone image hiding. By using the proposed method, the background image can be eliminated and the hidden visual pattern can be revealed precisely. Experimental results show that the decoded visual patterns could reveal good visual quality under various kinds of input patterns. Furthermore, better visual quality can be obtained when more halftone images are overlaid.
\end{abstract}

Key words: data hiding, error diffusion, halftone, visual cryptography.

\section{Introduction}

Data hiding methods for digital images have been widely studied by researchers. However, there are still a few existing techniques for data hiding in halftone images. Halftoning (Ulichney, 1987) is a technique for changing multi-tone images into two-tone binary images, which look like the original multi-tone images when viewing from a distance. Halftone images are commonly used in printing books, newspapers, magazines, and fax documents. There are two kinds of halftoning techniques. They are ordered dithering (Bayers, 1973) and error diffusion (Floyd and Steinberg, 1976; Jarvis et al., 1976; Stucki, 1981). Ordered dithering is a thresholding of the multi-tone image with a spatially periodic pattern. To dither an image, each pixel value is scaled and compared to a threshold in the corresponding element of the pattern, and if the pixel value is greater than the threshold, draw the pixel white; otherwise, draw it black. Fig. 1(a) shows a dithering Lena 
image using the Bayer's pattern:

$$
\left[\begin{array}{cccc}
0 & 8 & 2 & 10 \\
12 & 4 & 14 & 6 \\
3 & 11 & 1 & 9 \\
15 & 7 & 13 & 5
\end{array}\right]
$$

Error diffusion is more complicated than ordered dithering, but it achieves better visual quality. The halftoning error is fed forward to its adjacent neighbors using a specific kernel so that each pixel has effectively an adaptive threshold. Fig. 1(b) shows an error diffused Lena image using the Jarvis kernel:

$$
\left[\begin{array}{rrrrrr} 
& & * & 7 & 5 \\
3 & 5 & 7 & 5 & 3 \\
1 & 3 & 5 & 3 & 1
\end{array}\right]
$$

Naor and Shamir (1995) proposed visual cryptography in 1994. The key feature of this technique is that it can recover a secret image without any computation. It exploits the human visual system to recover the secret image from some overlapping shares. Recently, some data hiding techniques for error-diffused halftone images are proposed (Fu and $\mathrm{Au}$, 2002; Fu and Au, 2003a; Fu and Au, 2003b; Pei and Guo, 2003a; Pei and Guo, 2003b). Pei and Guo (2003a, 2003b) proposed a noise-balanced algorithm for hiding binary visual pattern into two or more error-diffused images. The first one is only a normal errordiffused image, and the others are achieved by applying the noise-balanced error diffusion technique ( $N B E D F)$ to the original multi-tone image. The binary visual pattern can be recovered without any computation when these two or more error-diffused images are overlaid. Thus the $N B E D F$ can be percepted as a kind of visual cryptography. However, the decoded visual pattern is not clear (Fig. 7), since it is blended with the background image.

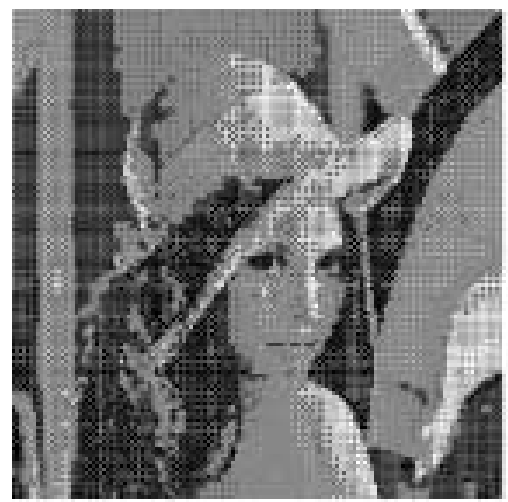

(a)

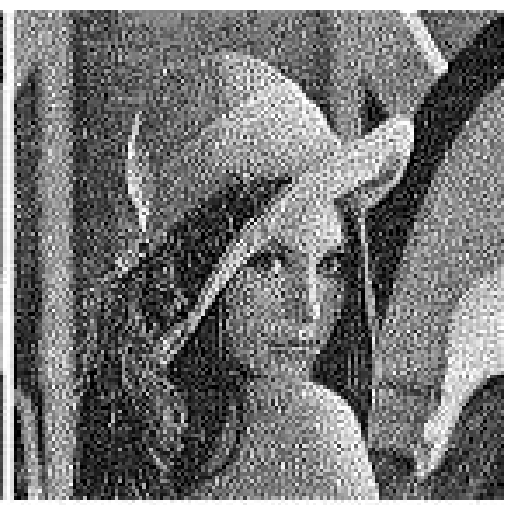

(b)

Fig. 1. Halftone images: (a) ordered dithering, (b) error diffusion. 
In this paper, an improved technique for halftone image hiding is proposed. The proposed method employs a modified overlapping algorithm which requires an additional low-complexity computation when overlapping. By using the proposed technique, the background image can be eliminated and the binary visual pattern can be recovered more precisely. Though the modified overlapping algorithm requires a little additional computation, the precise decoded visual pattern is worth the computation it paid. For example, the proposed technique can be applied to the mobile phone system for image authentication or conveying of secret messages. Since the mobile phone has computational limits inherently, the simple computation of the proposed method can fit for the mobile phone. In general, the traditional cryptography requires complex computation and thus it is hard to implement in the mobile phone. That is to say, the proposed method can provide a simple cryptography for the mobile phone.

This paper is organized as follows. In the next section, the $N B E D F$ is reviewed briefly. Section 3 presents our proposed method. Some experimental results are shown in Section 4. Finally, conclusions are stated in Section 5.

\section{A Review of the Noise-Balanced Error Diffusion}

In this section, we will review the noise-balanced error diffusion technique ( $N B E D F)$ (Pei and Guo, 2003a; Pei and Guo, 2003b). The standard error diffusion is shown in Fig. 2. The multi-tone image is halftoned line-by-line sequentially. The variable $x_{i j}$ represents the current input pixel at location $(i, j)$ and $x_{i j}^{\prime}$ is the sum of the diffused errors produced by previous neighboring pixels. The variable $u_{i j}$ is the sum of $x_{i j}$ and $x_{i j}^{\prime}$. The variable $b_{i j}$ is the binary output after thresholding. Here 255 is defined as a white pixel and 0 as a black pixel. The variable $e_{i j}$ is the difference between $u_{i j}$ and $b_{i j}$. The relationship between these variable can be described as follows:

$$
\begin{aligned}
& u_{i j}=x_{i j}+x_{i j}^{\prime}, \quad \text { where } x_{i j}^{\prime}=\sum h_{m n} \times x_{i-m, j-n}, \\
& e_{i j}=u_{i j}-b_{i j}, \quad \text { where } b_{i j}= \begin{cases}0, & u_{i j}<128, \\
255, & u_{i j} \geqslant 128\end{cases}
\end{aligned}
$$

Here, $h_{m n}$ represents the error diffusion kernel. The kernel determines the weighting of diffused error to the future pixels.

$N B E D F$ uses two halftone images ( $E D F 1$ and $E D F 2$ ) to hide the binary visual pattern $P$ which can be perceived directly from two overlaid halftone images. $E D F 1$ is generated by standard error diffusion to the original multi-tone image. $E D F 2$ is generated by applying $N B E D F$. Let $P_{W}$ be the set of all the white pixels in $P$, and $P_{B}$ be the set of all the black pixels in $P$. Similarly, $E D F 1_{W}$ and $E D F 1_{B}$ are defined as above. Then $E D F 2$ is generated line-by-line sequentially. If $E D F 1(i, j) \in E D F 1_{W}$ and $P(i, j) \in P_{B}$, then $E D F 2(i, j)$ should be processed with $N B E D F$. In $N B E D F$, Eqs. 1 and 2 are modified as follows.

$$
\begin{aligned}
& u_{i j}=x_{i j}+x_{i j}^{\prime}-N_{B} . \\
& e_{i j}=u_{i j}-b_{i j}+N_{B} .
\end{aligned}
$$




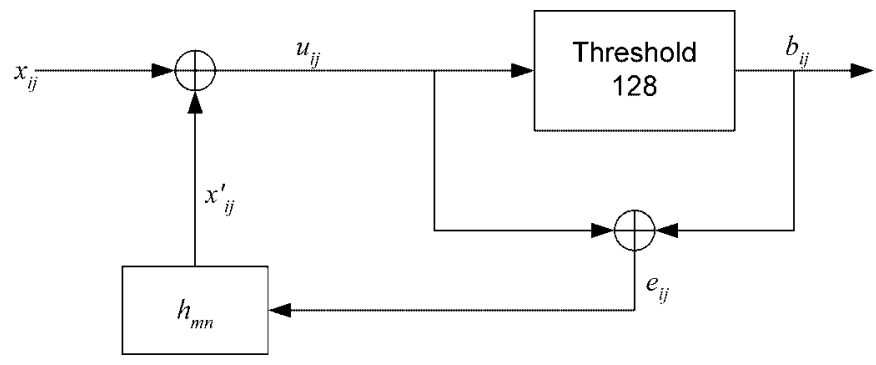

Fig. 2. Diagram of standard error diffusion.

Here $N_{B}$ is a constant variable. If $E D F 1(i, j) \in E D F 1_{W}$ and $\mathrm{P}(i, j) \in P_{W}$, then Eqs. 5 and 6 are applied as follows.

$$
\begin{aligned}
& u_{i j}=x_{i j}+x_{i j}^{\prime}+N_{B} . \\
& e_{i j}=u_{i j}-b_{i j}-N_{B} .
\end{aligned}
$$

If $E D F 1(i, j) \in E D F 1_{B}$ and $P(i, j) \in P_{W}$, then Eqs. 3 and 4 are applied. If $E D F 1(i, j) \in E D F 1_{B}$ and $P(i, j) \in P_{B}$, then Eqs. 1 and 2 are applied.

In $N B E D F, N_{B}$ could be tuned to determine the quality of $E D F 2$ image and the decoded binary visual pattern. If $N_{B}$ is increased, the quality of $E D F 2$ image will be degraded and the decoded binary pattern will be clearer, and vice versa. The experimental results shown in (Pei and Guo, 2003a; Pei and Guo, 2003b) reveal that the decoded visual pattern remains clear in the high texture image regions. However, it has poor contrast in the white regions. In fact, the quality of the decoded image depends on both the visual pattern and the background image, since the visual pattern is blended with the background image.

\section{Proposed Method}

In this section, an improved technique for halftone image hiding is proposed. The proposed method requires a little additional computation when overlapping. However, the computation is simple and the computation complexity is low. With the overlapping algorithm, the background image could be eliminated and the decoded visual pattern is more precise.

The overlapping algorithm in conventional visual cryptography is the human visual system. It can be seen in Fig. 3. The decoded pixel is white only if two white pixels are stacked. The modified overlapping algorithm in the proposed method looks slightly different as shown in Fig. 4. The decoded pixel is black when one white pixel and one black pixel are stacked. And the decoded pixel is white when two pixels with the same color are stacked. This procedure combined with the following modified $N B E D F$ can remove the background image in the decoded image so that the binary visual pattern is not blended with the background image. 


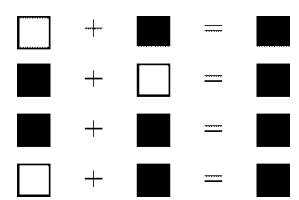

Fig. 3. Conventional visual cryptography.

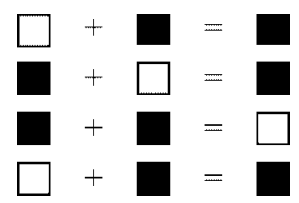

Fig. 4. Modified visual cryptography.

In the same way, the modified $N B E D F$ uses two halftone images $(E D F 1$ and $E D F 2$ ) to hide the binary visual pattern $P$. If $E D F 1(i, j) \in E D F 1_{W}$ and $P(i, j) \in$ $P_{B}$, then $E D F 2(i, j)$ is preferred to be a black pixel and should be processed with Eqs. 3 and 4. If $E D F 1(i, j) \in E D F 1_{B}$ and $P(i, j) \in P_{B}$, then $E D F 2(i, j)$ is preferred to be a white pixel and should be processed with Eqs. 5 and 6. If $\mathrm{P}(i, j) \in P_{W}$, then $E D F 2(i, j)$ is preferred to be identical to $E D F 1(i, j)$. In this case, three conditions should be considered as follows. Firstly, a trial on $E D F 2(i, j)$ is made by using standard error diffusion.

I. If $E D F 2(i, j)$ is identical to $E D F 1(i, j)$, then Eqs. 1 and 2 are applied.

II. If $E D F 2(i, j)$ is white and $E D F 1(i, j)$ is black, then Eqs. 3 and 4 are applied.

III. If $E D F 2(i, j)$ is black and $E D F 1(i, j)$ is white, then Eqs. 5 and 6 are applied.

With this strategy, we can obtain more precise decoded visual pattern without interference from the background image.

In addition, the number of $E D F$ images can be increased to provide better decoded visual pattern quality. The method is similar to the one described above. Consider the case of three $E D F$ images, if $E D F 1(i, j) \in E D F 1_{W}$ and $E D F 2(i, j) \in E D F 2_{W}$ and $P(i, j) \in P_{B}$, then $E D F 3(i, j)$ is preferred to be a black pixel and should be processed with Eqs. 3 and 4 . If $\left(E D F 1(i, j) \in E D F 1_{W}\right.$ and $E D F 2(i, j) \in E D F 2_{B}$ and $\left.P(i, j) \in P_{B}\right)$ or $\left(E D F 1(i, j) \in E D F 1_{B}\right.$ and $E D F 2(i, j) \in E D F 2_{W}$ and $P(i, j) \in$ $\left.P_{B}\right)$, then $E D F 3(i, j)$ is processed with standard error diffusion and Eqs. 1 and 2 are applied. If $E D F 1(i, j) \in E D F 1_{B}$ and $E D F 2(i, j) \in E D F 2_{B}$ and $P(i, j) \in P_{B}$, then $E D F 3(i, j)$ is preferred to be a white pixel and should be processed with Eqs. 5 and 6. If $\mathrm{P}(i, j) \in P_{W}$, then $E D F 3(i, j)$ is preferred to be identical to $E D F 1(i, j)$ and $E D F 2(i, j)$. In this case, three conditions should be considered as follows. Firstly, a trial on $E D F 3(i, j)$ is made by using standard error diffusion.

I. If $E D F 3(i, j)$ is white and both $E D F 1(i, j)$ and $E D F 2(i, j)$ are black, then Eqs. 3 and 4 are applied.

II. If $\operatorname{EDF} 3(i, j)$ is black and both $\operatorname{EDF} 1(i, j)$ and $E D F 2(i, j)$ are white, then Eqs. 5 and 6 are applied.

III. Otherwise, Eqs. 1 and 2 are applied. 
In general, the decoded visual pattern will reveal better quality when more EDF images are overlaid. The overlapping algorithm for more $E D F$ images is similar to that of two $E D F$ images. The decoded pixel is white when all pixels with the same color are stacked. Otherwise, the decoded pixel is black.

\section{Experimental Results}

The proposed method is tested on the $512 \times 512$ multi-tone Lena image. Fig. 5 shows Lena image and its $E D F$ image. The Jarvis kernel is used to diffuse the multi-tone image. In addition, some binary visual patterns to be embedded are shown in Fig. 6. These patterns differ individually. Fig. 7(a) shows the embedded halftone image using NBEDF and Fig. 8(a) shows the embedded halftone image using the proposed method. The balanced noise $N_{B}$ used here is 25 . It can be seen that the two pattern-embedded images have similar visual quality with no conspicuous artifacts. Then Fig. 5(b) and Fig. 7(a) are overlaid to generate Fig. 7(b) using NBEDF. The visual quality of the decoded pattern is good except for that in the white region. Similarly, Fig. 5(b) and Fig. 8(b) are overlaid to generate Fig. 8(b) using the proposed method. Without the interference of background image, the decoded binary visual pattern as shown in Fig. 8(b) is more precise.

In order to demonstrate the achievement and positive performance of our proposed method, the skeleton word is used in the experiment. Fig. 9(a) and Fig. 10(a) show the embedded halftone images using $N B E D F$ and the proposed method, respectively. Fig. 9(b) and Fig. 10(b) show the decoded images using $N B E D F$ and the proposed method, respectively. It can be seen that the decoded binary pattern obtained by $N B E D F$ is unclear, the high texture region especially. On the contrary, the decoded binary pattern obtained by the proposed method is clear.

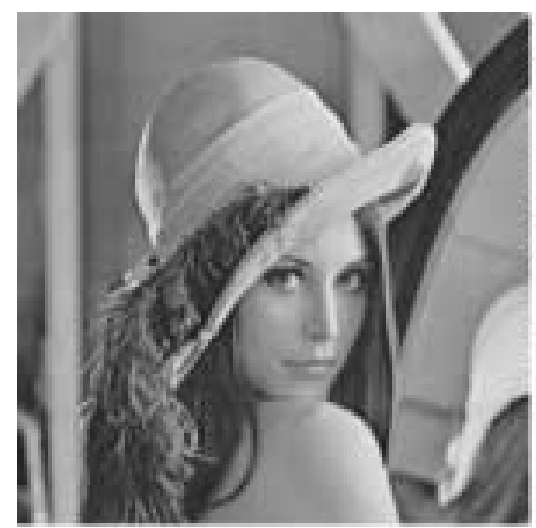

(a)

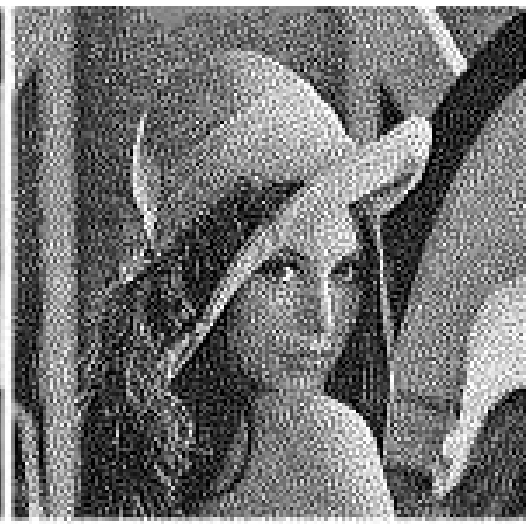

(b)

Fig. 5. Lena image: (a) multi-tone image, (b) error diffused image. 


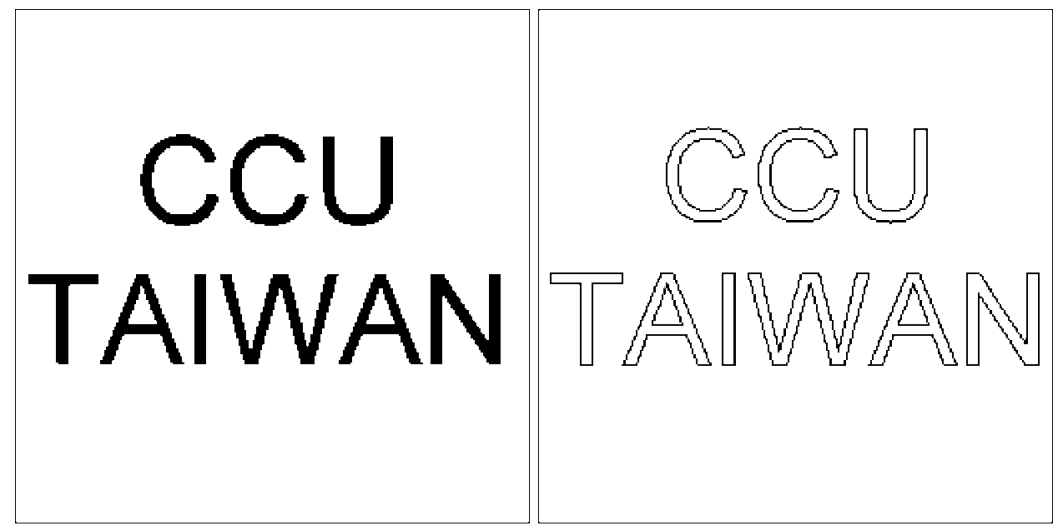

(a)

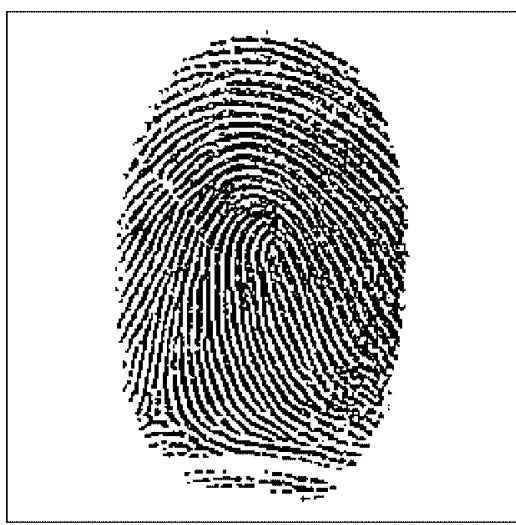

(c) (b)

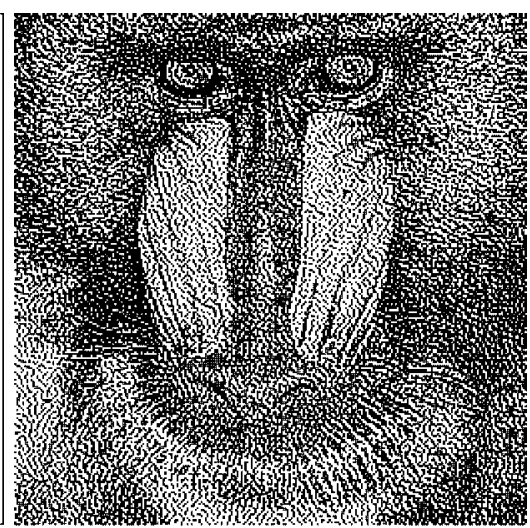

(d)

Fig. 6. Input visual patterns: (a) bold word, (b) skeleton word, (c) fingerprint image, (d) Halftone Baboon image.

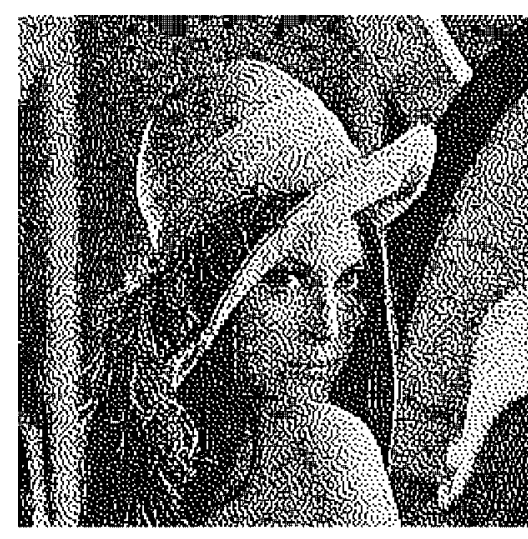

(a)

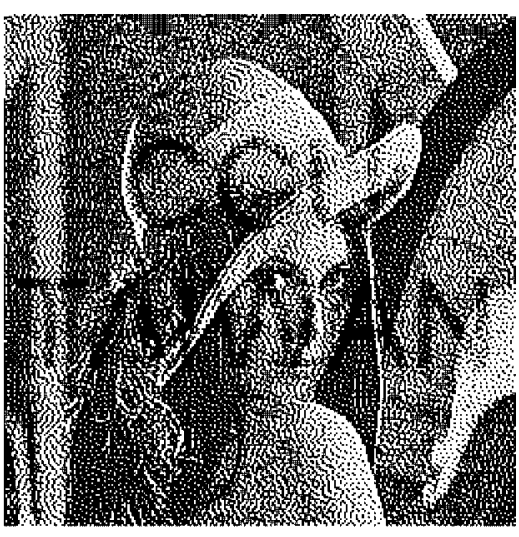

(b)

Fig. 7. $N B E D F$ using Fig. 6(a) as input pattern: (a) embedded image, (b) overlaid image. 


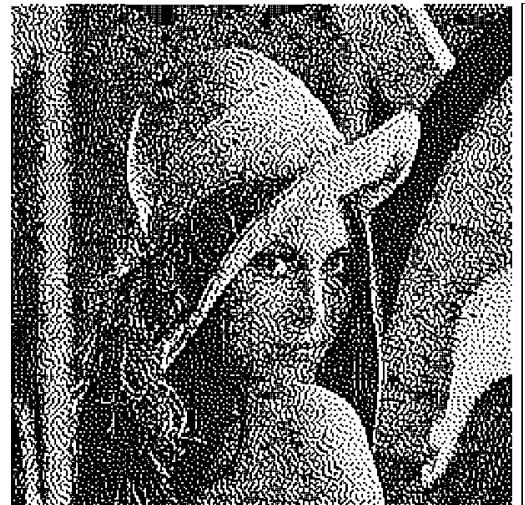

(a)

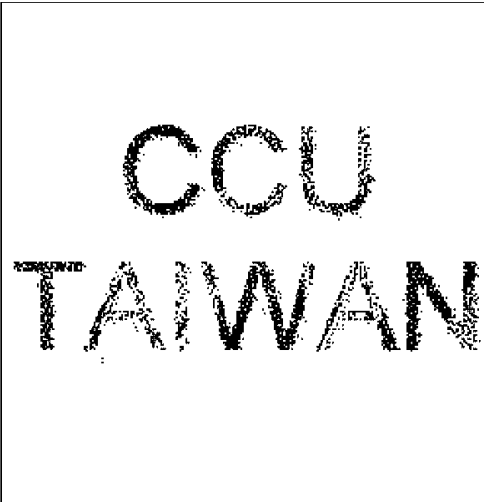

(b)

Fig. 8. The proposed method using Fig. 6(a) as input pattern: (a) embedded image, (b) overlaid image.

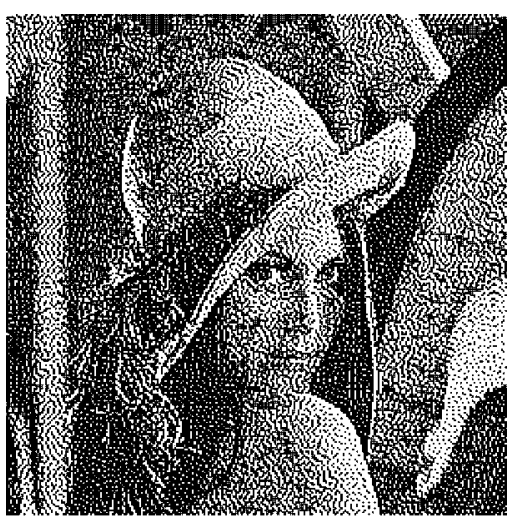

(a)

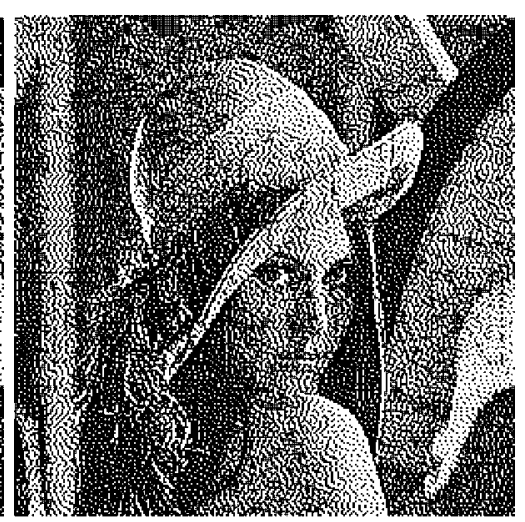

(b)

Fig. 9. $N B E D F$ using Fig. 6(b) as input pattern: (a) embedded image, (b) overlaid image.

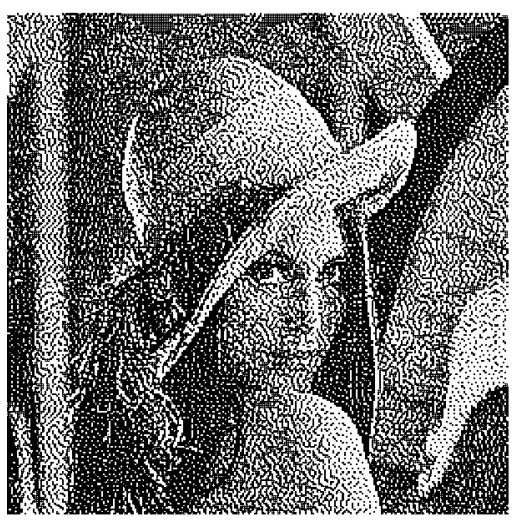

(a)

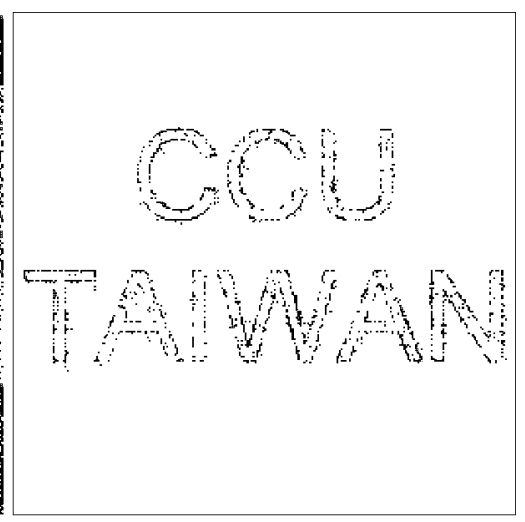

(b)

Fig. 10. The proposed method using Fig. 6(b) as input pattern: (a) embedded image, (b) overlaid image. 


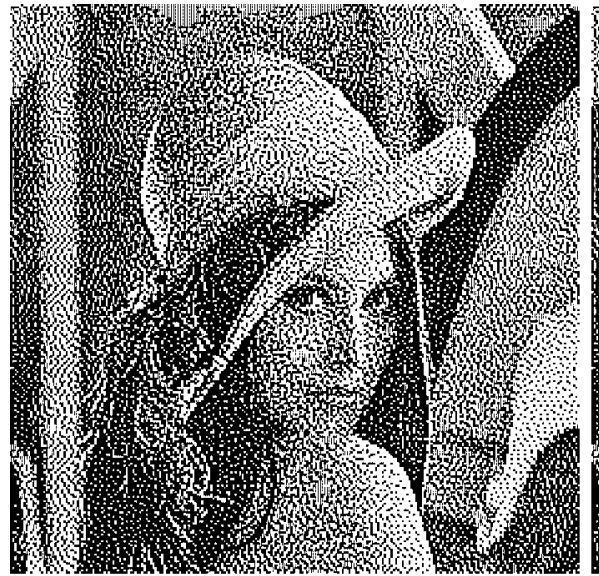

(a)

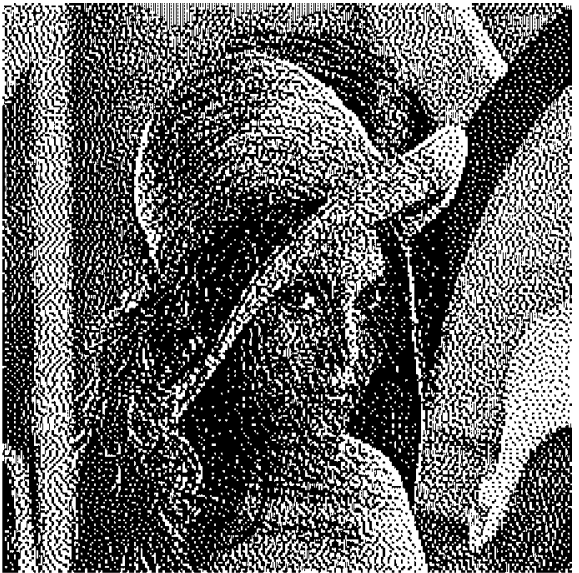

(b)

Fig. 11. NBEDF using Fig. 6(c) as input pattern: (a) embedded image, (b) overlaid image.

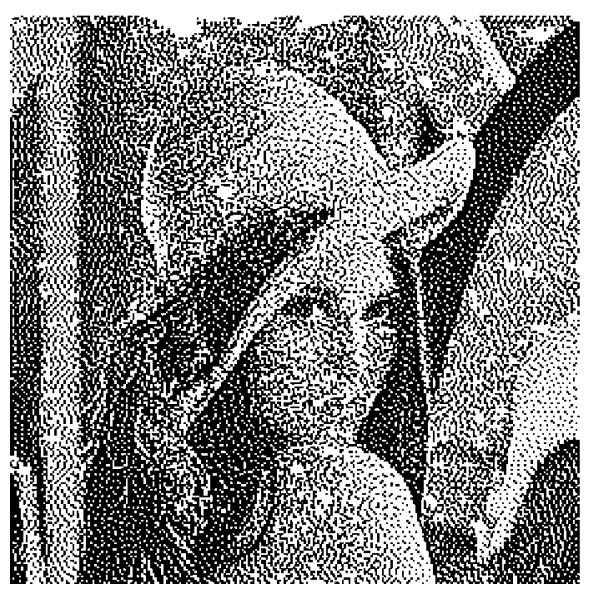

(a)

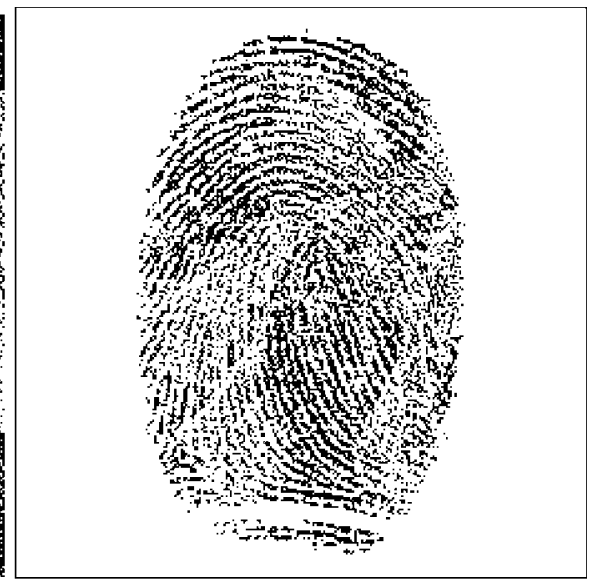

(b)

Fig. 12. The proposed method using Fig. 6(c) as input pattern: (a) embedded image, (b) overlaid image.

In Fig. 11 and Fig. 12, a fingerprint image is tested. Both the pattern-embedded images show a little visible artifact around the edge of the fingerprint. The decoded pattern obtained by the proposed method is identified to be better than that of $N B E D F$.

A halftone Baboon image is also used as the input visual pattern as shown in Fig. 6(d). The results are revealed in Fig. 13 and Fig. 14. The pattern-embedded images look in a state of confusion. But the hidden pattern is not perceivable. As the results of overlapping, the decoded image obtained by $N B E D F$ is unclear completely, but it is faintly visible using the proposed method. 


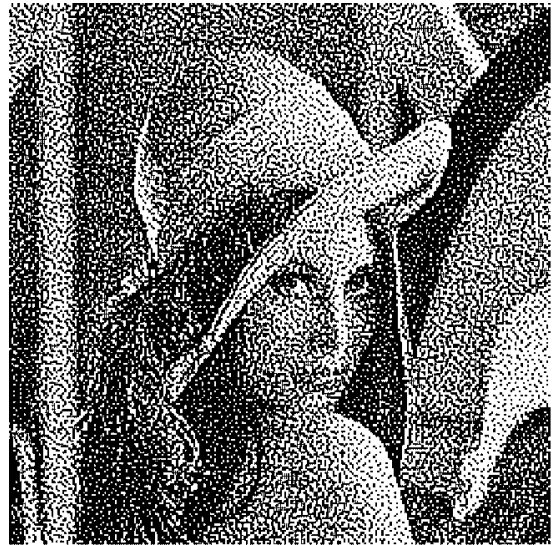

(a)

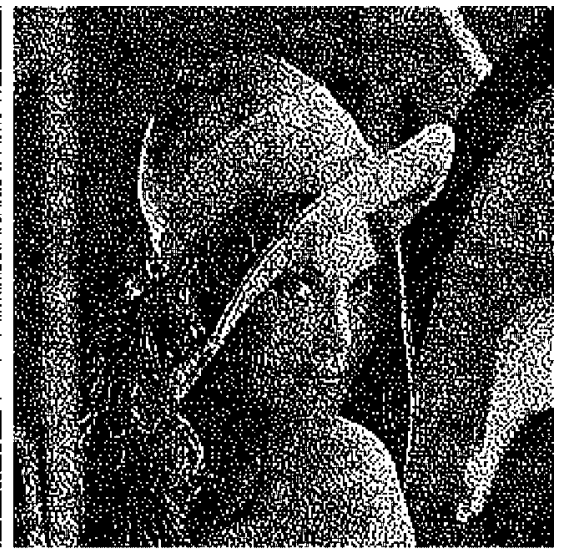

(b)

Fig. 13. NBEDF using Fig. 6(d) as input pattern: (a) embedded image, (b) overlaid image.

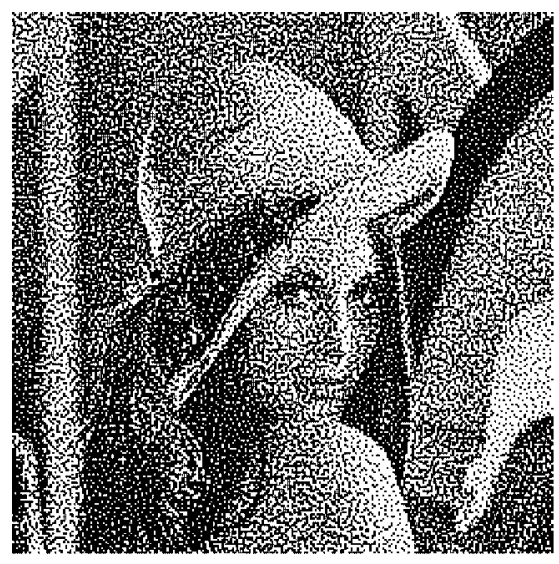

(a)

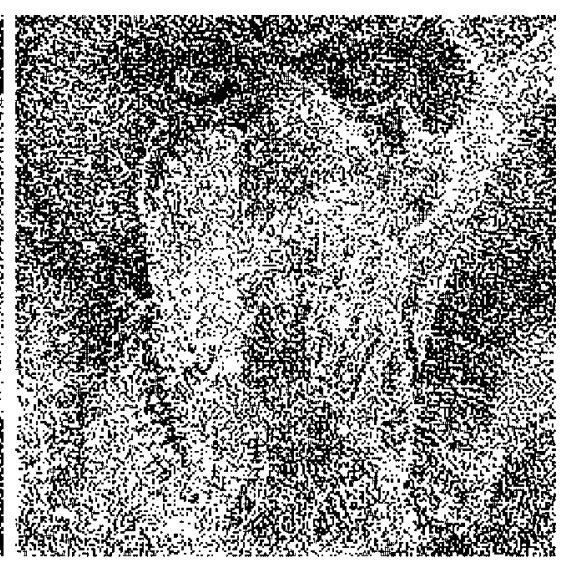

(b)

Fig. 14. The proposed method using Fig. 6(d) as input pattern: (a) embedded image, (b) overlaid image.

Furthermore, the better image quality can be obtained when more than two halftone images are overlaid. Fig. 15 shows the results when overlapping three halftone images. It can be seen that these decoded images are more precise than those of two halftone images.

\section{Conclusions}

In this paper, an improved method for halftone image hiding is proposed. Two or more error-diffused halftone images can be overlaid to recover the hidden binary visual pat- 


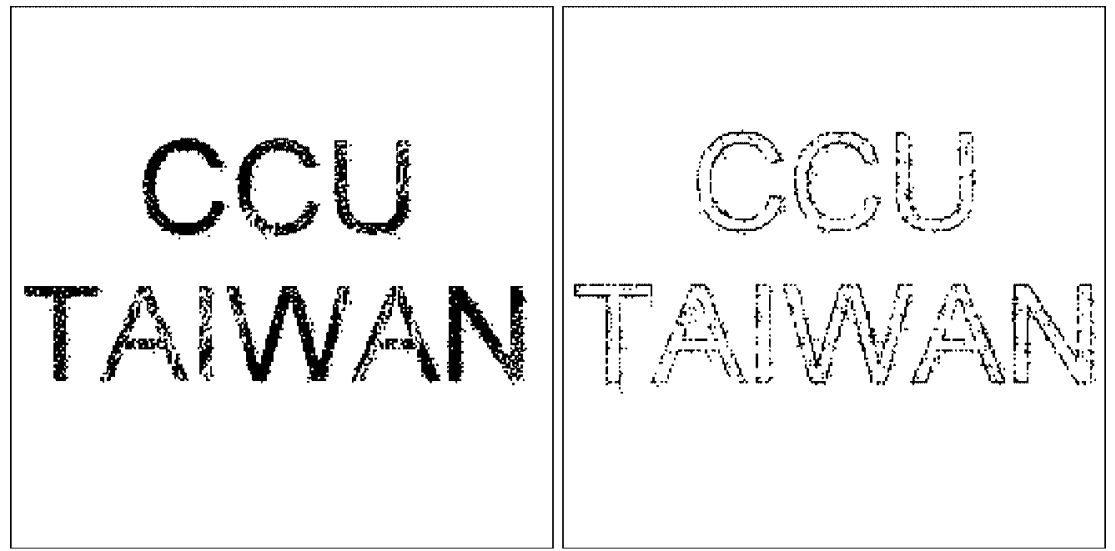

(a)

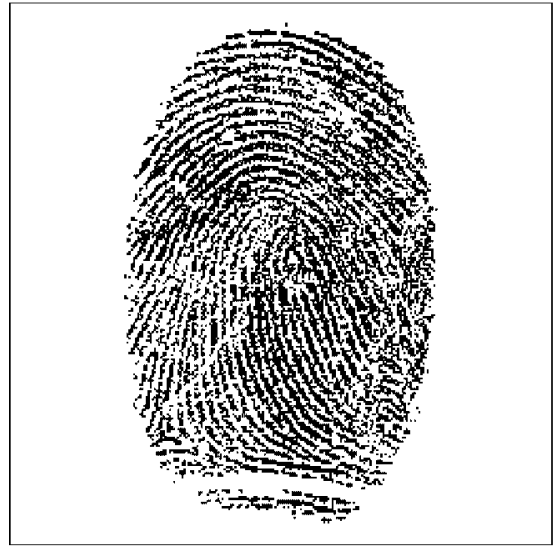

(c) (b)

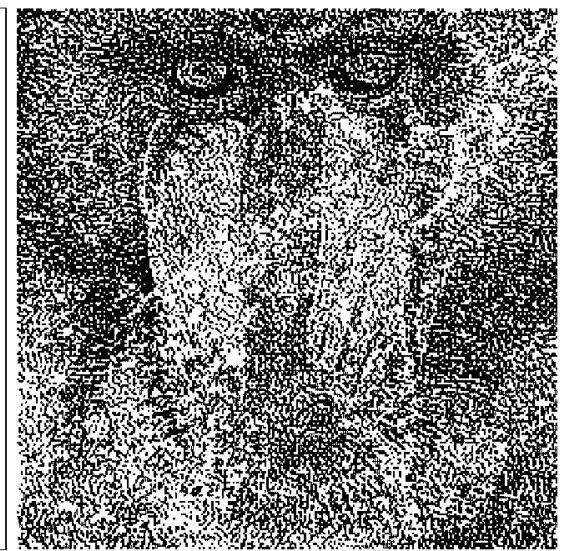

(d)

Fig. 15. The result images when overlapping three halftone images.

tern. By using the proposed method, the background image in the decoded image can be eliminated and the hidden binary visual pattern can be revealed precisely. However, a little additional computation is required by the modified overlapping algorithm. Since the complexity is low, the proposed method can be applied to mobile system for image authentication or conveying of secret messages. From the experimental results, the decoded visual patterns are precise under various kinds of input patterns.

\section{References}

Bayers, B.E. (1973). An optimum method for two level rendition of continuous tone pictures. In Proc. IEEE Int. Communication Conf. pp. 2611-2615.

Floyd, R.W., and L. Steinberg (1976). An adaptive algorithm for spatial grayscale. In Proc. SID. pp. 75-77. 
Fu, M.S., and O.C. Au (2002). Data hiding watermarking for halftone images. IEEE Trans. Image Processing, 11(4), 477-484.

Fu, M.S., and O.C. Au (2003a). A novel self-conjugate halftone image watermarking technique. In Proc. of IEEE Int. Sym. on Circuits and Systems, Vol. 3. pp. 790-793.

$\mathrm{Fu}$, M.S., and O.C. Au (2003b). Steganography in halftone images: conjugate error diffusion. Signal Processing, 83(10), 2171-2178.

Jarvis, J.F., C.N. Judice and W.H. Ninke (1976). A survey of techniques for the display of continuous-tone pictures on bilevel displays. In Comp. Graph. Image Proc., Vol. 5. pp. 13-40.

Noar, M., and A. Shamir (1995). Visual cryptography. In Advances in Cryptology - EUROCRYPT'94 Lecture Notes in Computer Science, Vol. 950. Springer, Berlin. pp. 1-12.

Pei, S.-C., and J.-M. Guo (2003a). Hybrid pixel-based data hiding and block-based watermarking for errordiffused halftone images. IEEE Trans. Circuits and System for Video Technology, 13(8), 867-884.

Pei, S.-C., and J.-M. Guo (2003b). Data hiding in halftone images with noise-balanced error diffusion. IEEE Signal Processing Letters, 10(12), 349-351.

Stucki, P. (1981). MECCA - A Multiple-Error Correcting Computation Algorithm for Bilevel Image Hardcopy Reproduction. IBM Res. Lab., Zurich, Switzerland, Res. Rep. RZ1060.

Ulichney, R. (1987). Digital Halftoning. Cambridge, MA: MIT Press.

H.-W. Tseng received the BS degree in computer science and information engineering from Tamkang University, Taipei County, Taiwan, in 1986, and his MS degree in computer science and information engineering from National Taiwan University, Teipei, Taiwan, in 1988. He received his $\mathrm{PhD}$ degree in computer science and information engineering in 2005 from National Chung Cheng University, Chaiyi, Taiwan. His research interests include image processing, data hiding, watermarking, and error resilient coding.

C.-C. Chang received the BS degree in applied mathematics in 1977 and his MS degree in computer and decision science in 1979 from National Tsing Hua University, Hsinchu, Taiwan. He received his $\mathrm{PhD}$ degree in computer engineering in 1982 from National Chiao Tung University, Hsinchu, Taiwan. Dr. Chang is a fellow of IEEE and a member of Chinese Language Computer Society, Chinese Institute of Engineers of Republic of China, and Phi Tau Phi Society of Republic of China. His research interests include computer cryptography, data engineering, and image compression.

\section{Duomenų slėpimas dvilygiuose vaizduose}

\section{Hsien-Wen TSENG, Chin-Chen CHANG}

Dauguma darbuu apie dvilygiu vaizdu kriptografija skirti kontrastingesnio dekoduoto vaizdo gavimo tematikai. Tačiau paslèptasis piešinys dažnai susilieja su fono vaizdu ji sugadindamas. Šiame straipsnyje siūlomas pagerintas dvilygiu vaizdu slépimo metodas. Jị naudojant fono vaizdas eliminuojamas, todèl paslèptasis vaizdas gali būti atstatomas tiksliai. Eksperimentų rezultatai rodo, kad gaunami geros kokybès dekoduoti vaizdai ịvairaus pobūdžio pradiniams vaizdams. Dar geresnè vaizdų kokybėe gaunama, kai uždedami keli dvilygiai vaizdai. 